Supporting Information for:

Electrostatic Control of the Three-Dimensional Confined Assembly of Charged Block Copolymers in Emulsion Droplets

Min Ren, Zaiyan Hou, Xihuang Zheng, Jiangping Xu, * and Jintao Zhu*

Key Laboratory of Materials Chemistry for Energy Conversion and Storage, Ministry of Education (HUST), School of Chemistry and Chemical Engineering, Huazhong University of Science and Technology (HUST), Wuhan 430074, China

*Corresponding authors: Jiangping Xu, Jintao Zhu

E-mail: jiangpingxu@hust.edu.cn (J.X); jtzhu@mail.hust.edu.cn (J.Z) 


\section{Supporting Table:}

Table S1. Details of the Preparation of Charged Block Copolymer by Controlling the Reaction Time.

\begin{tabular}{|c|c|c|}
\hline Block copolymer & Reaction time (h) & Degree of quaternization (\%) \\
\hline $\mathrm{PS}_{9.8 \mathrm{~K}}-b-\mathrm{P} 4 \mathrm{VP}_{10 \mathrm{~K}} \mathrm{Q}^{\mathrm{2} .5 \%}$ & $1 \mathrm{~h}$ & 2.5 \\
\hline $\mathrm{PS}_{9.8 \mathrm{~K}}-b-\mathrm{P} 4 \mathrm{VP}_{10 \mathrm{~K}} \mathrm{Q}^{4} \%$ & $2 \mathrm{~h}$ & 4 \\
\hline $\mathrm{PS}_{9.8 \mathrm{~K}}-b-\mathrm{P} 4 \mathrm{VP}_{10 \mathrm{~K}} \mathrm{Q} 7 \%$ & $3 \mathrm{~h}$ & 7 \\
\hline $\mathrm{PS}_{9.8 \mathrm{~K}}-b-\mathrm{P} 4 \mathrm{VP}_{10 \mathrm{~K}} \mathrm{Q}^{\mathrm{Q}} \%$ & $4 \mathrm{~h}$ & 12 \\
\hline $\mathrm{PS}_{9.8 \mathrm{~K}}-b-\mathrm{P} 4 \mathrm{VP}_{10 \mathrm{~K}} \mathrm{Q}^{28 \%}$ & $5 \mathrm{~h}$ & 28 \\
\hline $\mathrm{PS}_{51 \mathrm{~K}}-b-\mathrm{P} 4 \mathrm{VP}_{18 \mathrm{~K}} \mathrm{Q7 \%}$ & $4 \mathrm{~h}$ & 7 \\
\hline $\mathrm{PS}_{51 \mathrm{~K}}-b-\mathrm{P} 4 \mathrm{VP}_{18 \mathrm{~K}} \mathrm{Q}^{\mathrm{Q} 16 \%}$ & $5 \mathrm{~h}$ & 16 \\
\hline $\mathrm{PS}_{51 \mathrm{~K}}-b-\mathrm{P} 4 \mathrm{VP}_{18 \mathrm{~K}} \mathrm{Q}^{\mathrm{Q} 26 \%}$ & $8 \mathrm{~h}$ & 26 \\
\hline $\mathrm{PS}_{17 \mathrm{~K}}-b-\mathrm{P} 4 \mathrm{VP}_{49 \mathrm{~K}} \mathrm{Q} 5 \%$ & $0.15 \mathrm{~h}$ & 5 \\
\hline $\mathrm{PS}_{17 \mathrm{~K}}-b-\mathrm{P} 4 \mathrm{VP}_{49 \mathrm{~K}} \mathrm{Q} 11 \%$ & $0.25 \mathrm{~h}$ & 11 \\
\hline $\mathrm{PS}_{17 \mathrm{~K}}-b-\mathrm{P} 4 \mathrm{VP}_{49 \mathrm{~K}} \mathrm{Q} 18 \%$ & $1 \mathrm{~h}$ & 18 \\
\hline $\mathrm{PS}_{17 \mathrm{~K}}-b-\mathrm{P} 4 \mathrm{VP}_{49 \mathrm{~K}} \mathrm{Q}^{\mathrm{Q} 4 \%}$ & $2 \mathrm{~h}$ & 24 \\
\hline
\end{tabular}




\section{Supporting Figures:}

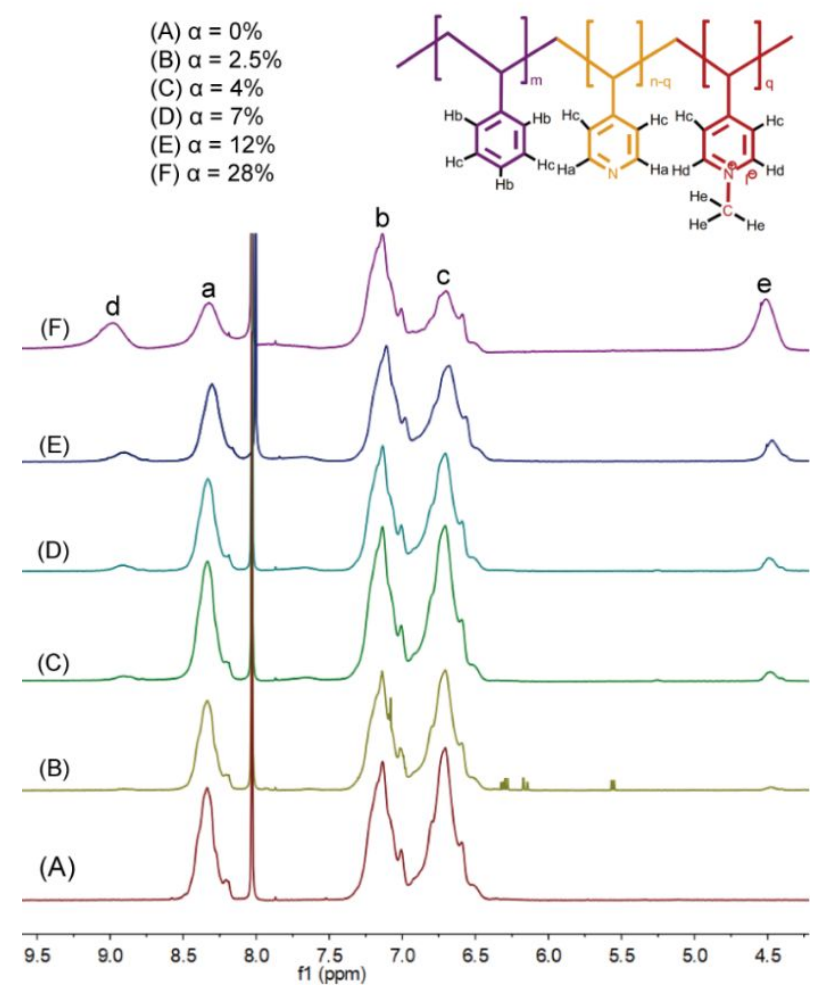

Figure S1. ${ }^{1} \mathrm{HNMR}$ spectra of $\mathrm{PS}_{9.8 \mathrm{~K}}-b-\mathrm{P} \mathrm{VP}_{10 \mathrm{~K}} \mathrm{Q}$ having different $\alpha$ values collected in $N, N$ dimethylformamide-d7.
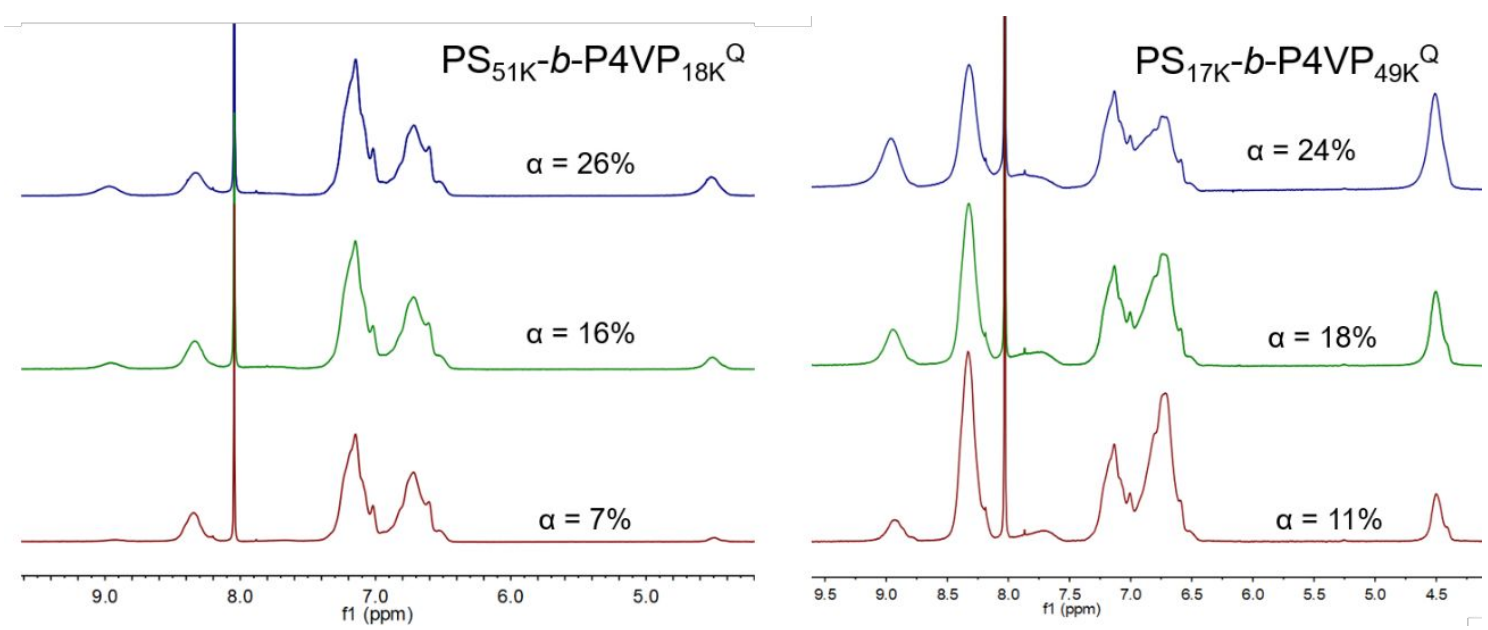

Figure S2. ${ }^{1} \mathrm{HNMR}$ spectra of $\mathrm{PS}_{51 \mathrm{~K}}-b-\mathrm{P}_{4} \mathrm{VP}_{18 \mathrm{~K}} \mathrm{Q}$ and $\mathrm{PS}_{17 \mathrm{~K}}-b-\mathrm{P}_{4} \mathrm{VP}_{49 \mathrm{~K}}{ }^{\mathrm{Q}}$ having different $\alpha$ values collected in $N, N$-dimethylformamide-d7. 

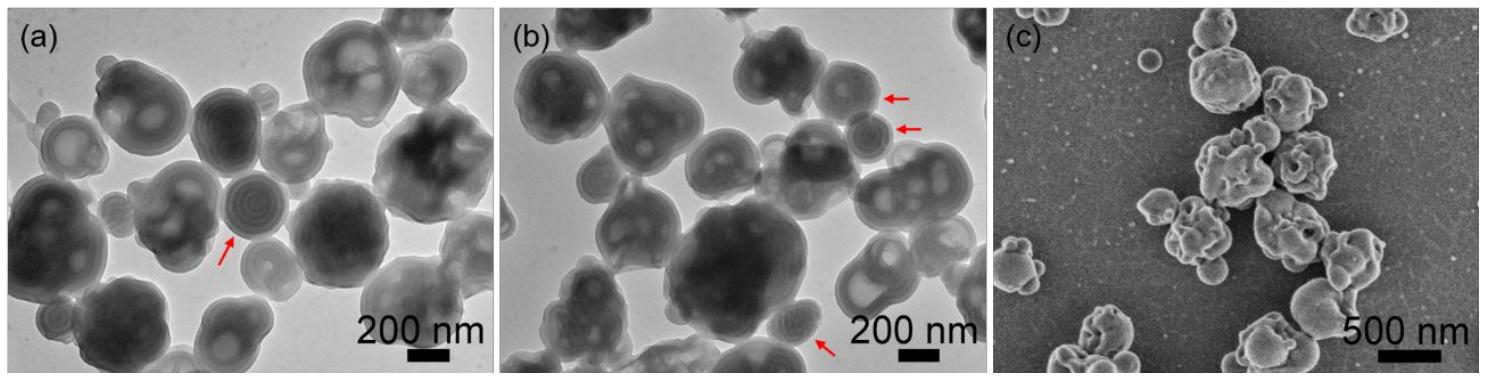

Figure S3. TEM (a, b) and SEM (c) images of $\mathrm{PS}_{9.8 \mathrm{~K}}-b-\mathrm{P}_{4} \mathrm{VP}_{10 \mathrm{~K}} \mathrm{Q}$ particles when $\alpha=7 \%$. The red arrows indicate the very small amount of onion-like structure and other structures.

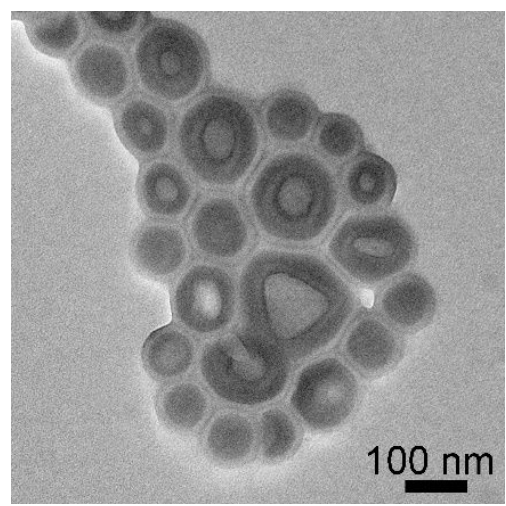

Figure S4. TEM image of $\mathrm{PS}_{9.8 \mathrm{~K}}-b-\mathrm{P} 4 \mathrm{VP}_{10 \mathrm{~K}} \mathrm{Q}$ assemblies when $\alpha=48 \%$, obtained by $3 \mathrm{D}$ confined assembly.

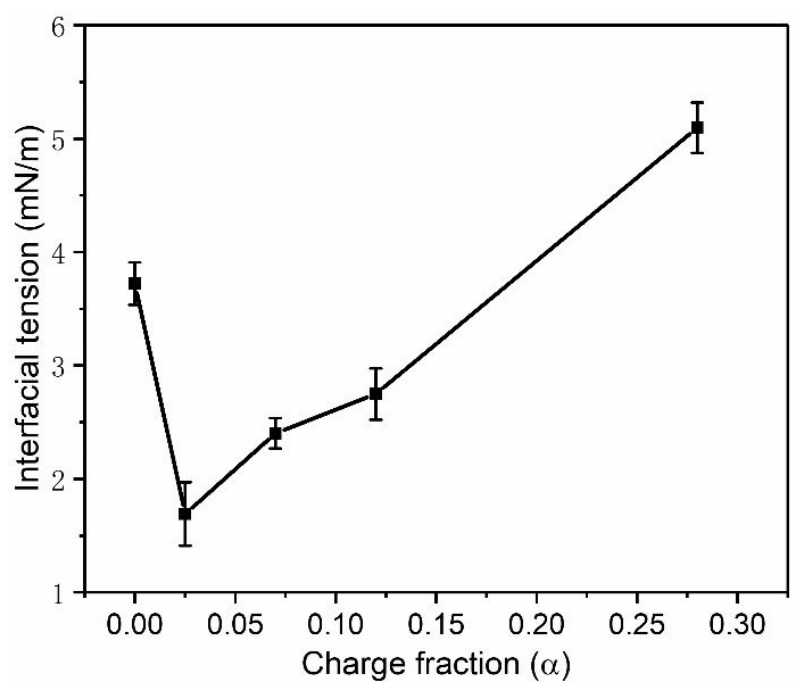

Figure S5. Plot showing the interfacial tension of oil/water interface as a function of charge fraction of $\mathrm{PS}_{9.8 \mathrm{~K}}-b-\mathrm{P} 4 \mathrm{VP}_{10 \mathrm{~K}} \mathrm{Q}$. Oil phase: $\mathrm{PS}_{9.8 \mathrm{~K}}-b-\mathrm{P} 4 \mathrm{VP}_{10 \mathrm{~K}}{ }^{\mathrm{Q}}$ in chloroform, $10 \mathrm{mg} / \mathrm{mL}$. Water phase: PVA in 
water, $3 \mathrm{mg} / \mathrm{mL}$.
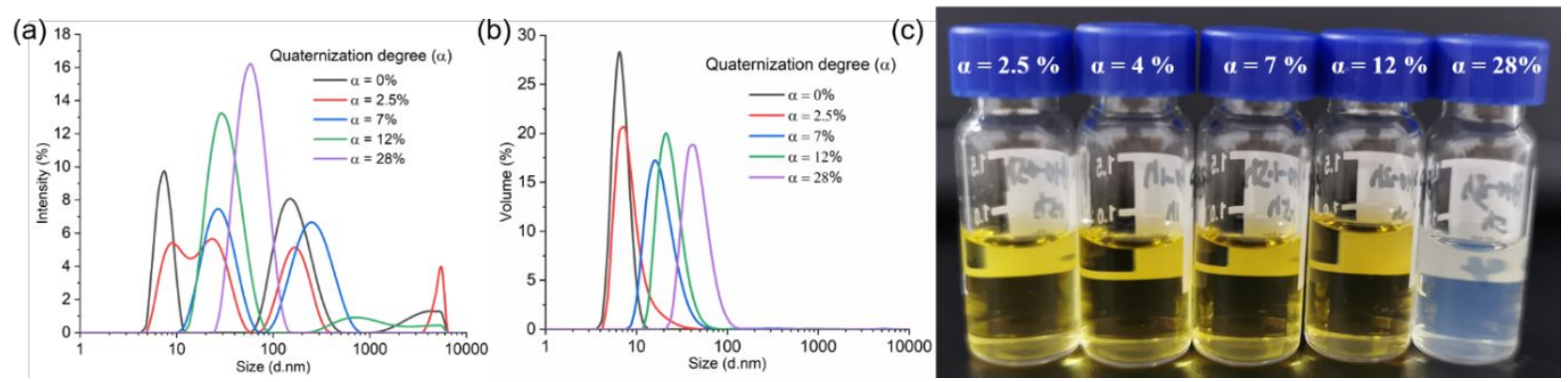

Figure S6. $(\mathrm{a}, \mathrm{b}) \mathrm{DLS}$ plots showing the formation of micelles of $\mathrm{PS}_{9.8 \mathrm{~K}}-b-\mathrm{P}_{4} \mathrm{VP}_{10 \mathrm{~K}} \mathrm{Q}$ in chloroform (10 mg/mL). (c) Photographs of the chloroform solution of $\mathrm{PS}_{9.8 \mathrm{~K}}-b-\mathrm{P}_{4} \mathrm{VP}_{10 \mathrm{~K}} \mathrm{Q}^{\mathrm{g}}$ having different $\alpha$ values.
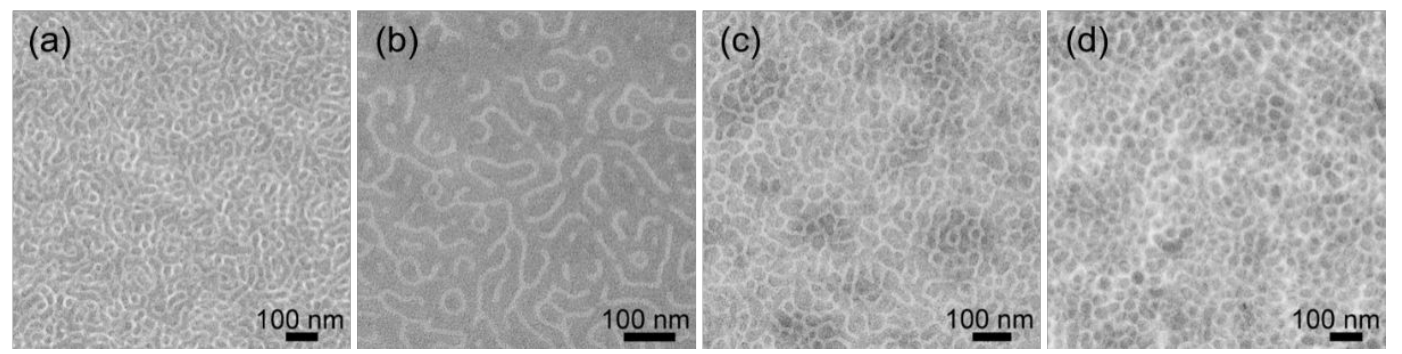

Figure S7. TEM images of $\mathrm{PS}_{9.8 \mathrm{~K}}-b-\mathrm{P} 4 \mathrm{VP}_{10 \mathrm{~K}} \mathrm{Q}^{\mathrm{Q}}$ films having different quaternization degrees ( $\alpha$ ): (a) $\alpha$ $=2.5 \%$; (b) $\alpha=7 \%$; (c) $\alpha=12 \%$; (d) $\alpha=28 \%$. The samples were selectively stained by iodine vapor before TEM observation.
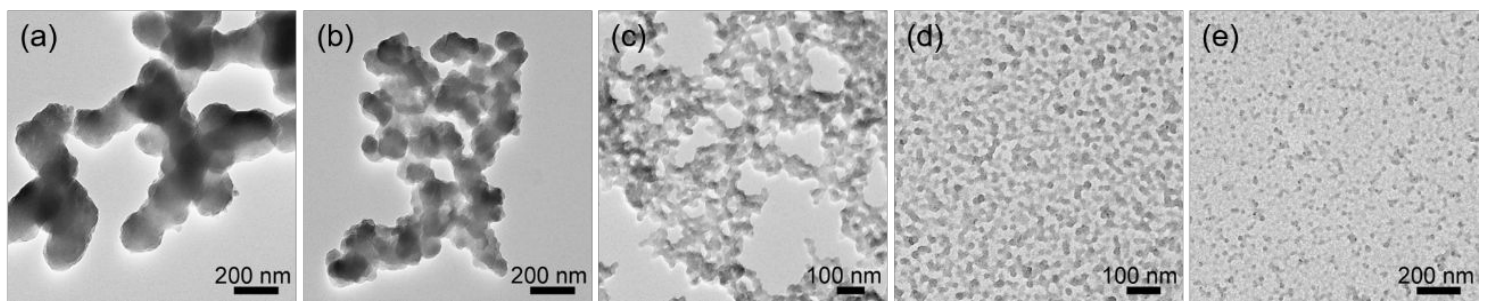

Figure S8. TEM images for the aggregates obtained by assembling $\mathrm{PS}_{9.8 \mathrm{~K}}-b-\mathrm{P}_{4} \mathrm{VP}_{10 \mathrm{~K}} \mathrm{Q}^{\mathrm{Q}}$ in solution: (a) 
$\alpha=0 \%$;(b) $\alpha=2.5 \%$; (c) $\alpha=7 \%$; (d) $\alpha=12 \%$; (e) $\alpha=28 \%$.

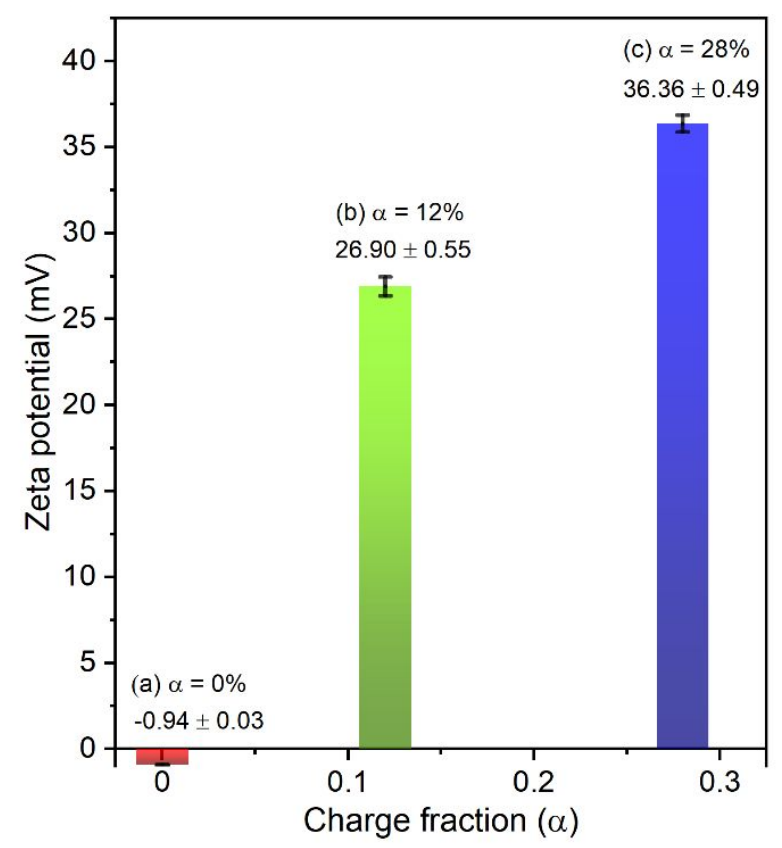

Figure S9. Zeta potential of the assemblies of $\mathrm{PS}_{9.8 \mathrm{~K}}-b-\mathrm{P}_{4 \mathrm{VP}} \mathrm{PK}_{10 \mathrm{Q}}$ dispersed in DI water. (a) $\alpha=0 \%$;

(b) $\alpha=12 \%$; (c) $\alpha=28 \%$.

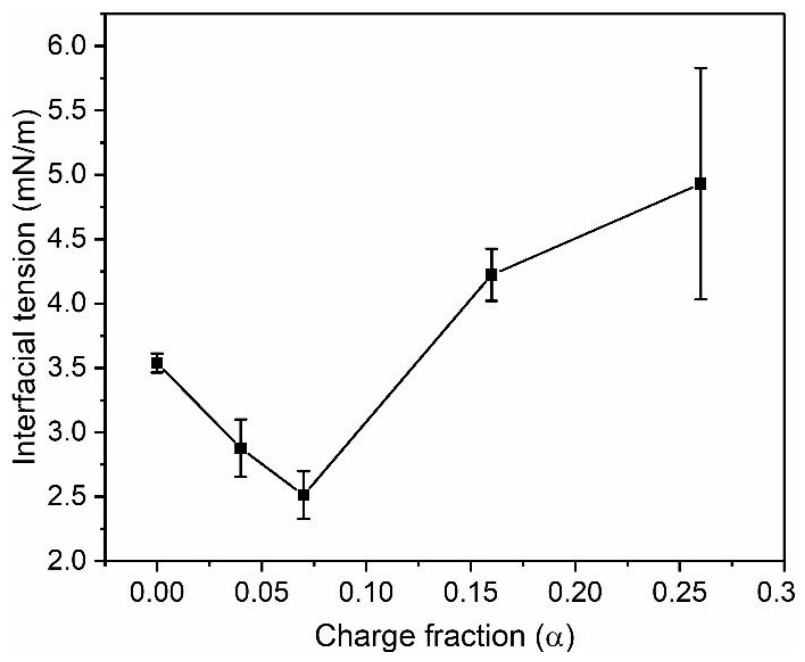

Figure S10. Plot showing the interfacial tension of oil/water interface as a function of charge fraction of $\mathrm{PS}_{51 \mathrm{~K}}-b-\mathrm{P} 4 \mathrm{VP}_{18 \mathrm{~K}} \mathrm{Q}$. Oil phase: $\mathrm{PS}_{51 \mathrm{~K}}-b-\mathrm{P}_{4 V \mathrm{P}_{18 \mathrm{~K}}} \mathrm{Q}$ in chloroform, $10 \mathrm{mg} / \mathrm{mL}$. Water phase: PVA in water, $3 \mathrm{mg} / \mathrm{mL}$. 


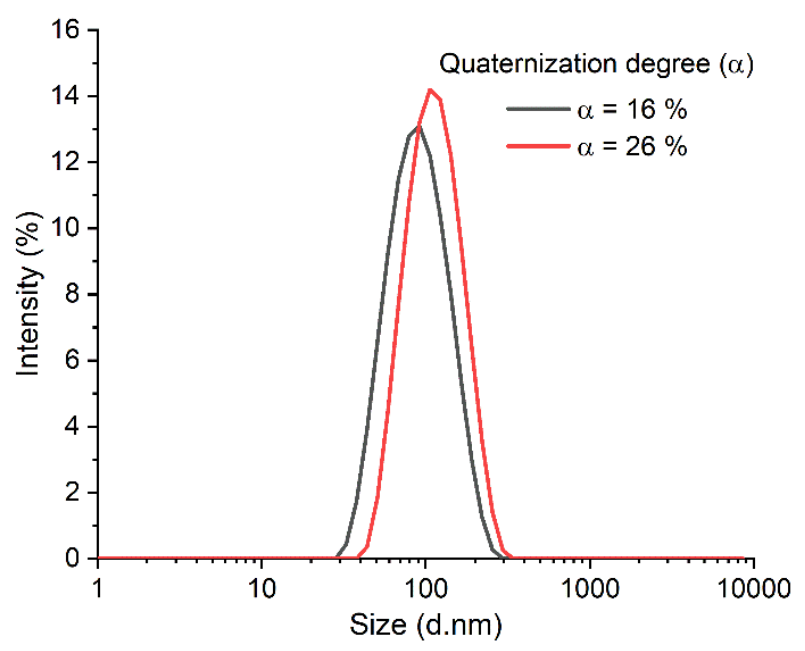

Figure S11. DLS plots showing the formation of $\mathrm{PS}_{51 \mathrm{~K}}-b-\mathrm{P}_{4} \mathrm{VP}_{18 \mathrm{~K}}{ }^{\mathrm{Q}}$ micelles in chloroform.

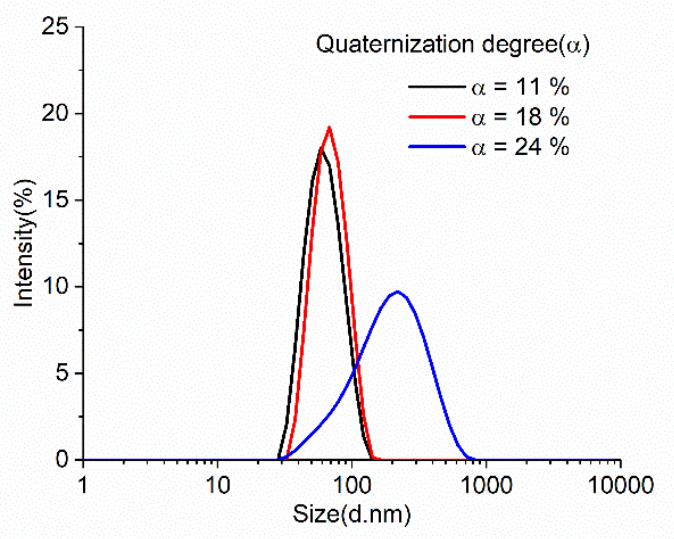

Figure S12. DLS plots showing the formation of $\mathrm{PS}_{17 \mathrm{~K}}-b-\mathrm{P} 4 \mathrm{VP}_{49 \mathrm{~K}}^{\mathrm{Q}}$ micelles in chloroform. 


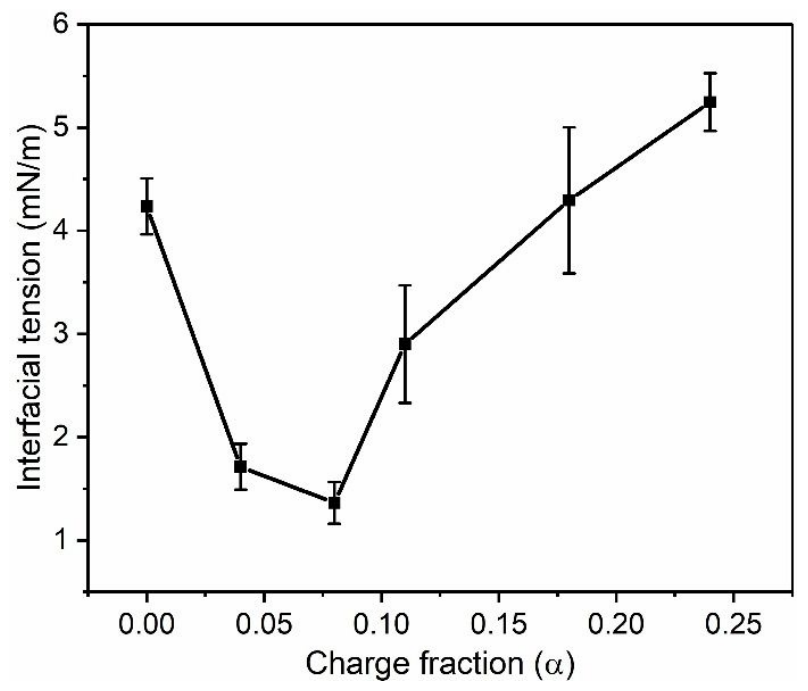

Figure S13. Plot showing the interfacial tension of oil/water interface as a function of charge fraction of $\mathrm{PS}_{17 \mathrm{~K}}-b-\mathrm{P} 4 \mathrm{VP}_{49 \mathrm{~K}} \mathrm{Q}$. Oil phase: $\mathrm{PS}_{17 \mathrm{~K}}-b-\mathrm{P}_{4 \mathrm{VP}_{49 \mathrm{~K}}} \mathrm{Q}^{\mathrm{Q}}$ in chloroform, $10 \mathrm{mg} / \mathrm{mL}$. Water phase: PVA in water, $3 \mathrm{mg} / \mathrm{mL}$.

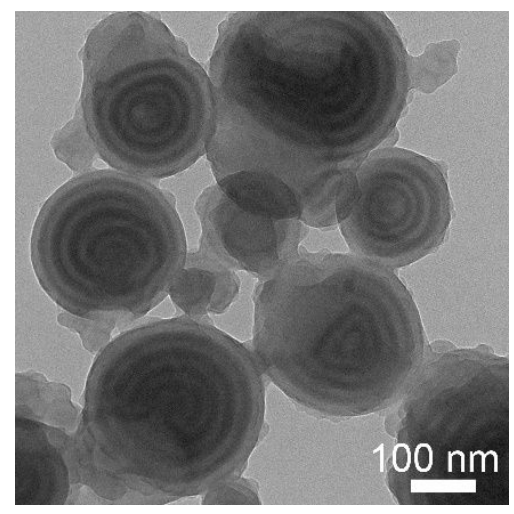

Figure S14. TEM image of $\mathrm{PS}_{9.8 \mathrm{~K}}-b-\mathrm{P} 4 \mathrm{VP}_{10 \mathrm{~K}}{ }^{\mathrm{Q} 2.5 \%}$ obtained by $3 \mathrm{D}$ confined assembly. The concentration of $\mathrm{NaCl}$ in the PVA aqueous solution was $100 \mathrm{mM}$. 


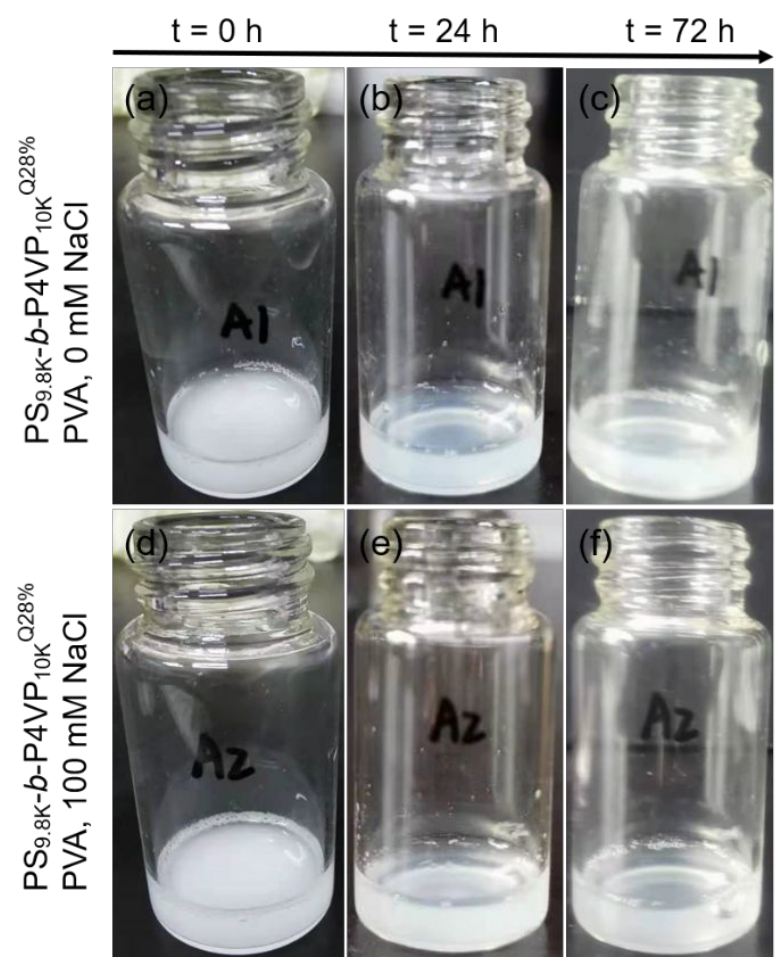

Figure S15. Photographs of the emulsions containing $\mathrm{PS}_{9.8 \mathrm{~K}}-b-\mathrm{P} 4 \mathrm{VP}_{10 \mathrm{~K}}{ }^{\mathrm{Q} 28 \%}$. The concentrations of $\mathrm{NaCl}$ in the PVA aqueous solution were: $(\mathrm{a}-\mathrm{c}) c_{\mathrm{NaCl}}=0 \mathrm{mM},(\mathrm{d}-\mathrm{f}) c_{\mathrm{NaCl}}=100 \mathrm{mM}$. 